International Journal of Agriculture, Environment and Bioresearch

Vol. 06, No. 03; 2021

ISSN: $2456-8643$

\title{
MAINIOC PRODUCTION CONSTRAINTS IN THE BOROUGH OF GLO-DJIGBE COMMON OF ABOMEY-CALAVI IN BENIN (WEST AFRICA)
}

\author{
WOKOU C. Guy \\ Pierre PAGNEY Laboratory, Climate, Water, Ecosystem and Development (LACEEDE) \\ Department of Geography and Regional Planning (DGAT)
}

https://doi.org/10.35410/IJAEB.2021.5646

\begin{abstract}
This research analyzes the constraints linked to cassava cultivation in the district of GoloDjigbé.

The data used for this research are: data on cassava cultivation techniques. They made it possible to have a perfect knowledge of cultivation techniques; climatological data: these are the monthly and annual rainfall amounts for the district of Glo-djigbé which were extracted from the database of the Agency for Air Safety and Navigation in Africa and Madagascar (ASECNA ) over the period from 1985 to 2015. In addition, the socio-demographic data from 2002 and 2013 with an estimate in 2025 taken from the INSAE databases which made it possible to determine the sampling and the socio-anthropological data from the surveys. ground.

The results of this research show that cassava is easy to grow but it is necessary to work the land well, to loosen it so that the roots develop without obstruction, given the fact that it is often cultivated with other crops at maturity. faster (corn, okra, peanuts). The climate handicaps constitute the natural constraints to the cultivation of cassava. Cassava is therefore a crop very vulnerable to the water deficit of the soil during the three months following its planting. Water stress at any time during this initial period greatly reduces the growth of roots and young shoots compromising subsequent development of tuberous roots even if drought stress is subsequently remedied. In addition, insufficient abundant labor, lack of credit and microcredit, lack of supervision of producers and poor use of income represent the socioeconomic factors that influence cassava production in the said arrondissement. The development of land with rudimentary techniques and the insecurity of producers on the land they exploit is a factor limiting cassava production but also the loss of soil fertility.
\end{abstract}

Keywords: Benin, Golo-Djigbé district, constraints, cassava, labor.

\section{INTRODUCTION}

Cassava is produced almost everywhere and is an integral part of the ten food crops in the world. It is a plant native to South America whose roots very rich in starch constitute a real source of inexpensive calories for millions of people in Africa in general and in Benin in particular (Agbandji, 2015). In Africa agriculture is the most important activity practiced especially in rural areas. Cassava is an undemanding plant that is most often grown at the end of the rotation or in combination with cereals (Kadedji, 2013). However, several crops are cultivated by producers 
and among these are maize, rice, wheat, potatoes and cassava which is one of the most widely cultivated crops in Africa. 2020, cassava will contribute nearly 44\% to income and technological change (Ahossi, 2008). It is also the most popular staple food. The research and work carried out in this sector by researchers is intense and suggests that cassava with high potential could help ensure food self-sufficiency in several nations. It is one of the main priority crops identified by the government of Benin in the special agricultural sector revival program (LARES, 2013). It is available in the fields all year round and could be uprooted for any use at any time. In addition, cassava-based food products (gari, tapioca, lafou, and others) are an integral part of the products that Benin exports to the regional market (LARES, 2013). This plant, which is already proving its worth in Benin, particularly in the Atlantic department and in particular in the Arrondissement of Golo-Djigbé (commune of Abomey-Calavi). In the locality, cassava is one of the most interesting food crops for farmers and consumers alike, and the most processed basic raw material. However, human and social, technical, economic, Institutional and climatic constraints do not guarantee optimal productivity of this speculation. The research medium is located between $6^{\circ} 30$ "and $^{\circ} 35^{\prime \prime} \mathrm{N}$ latitude and between $2^{\circ} 15^{\prime \prime}$ and $2^{\circ} 30^{\prime \prime} \mathrm{E}$ longitude (Figure 1). The objective of this research is to analyze the constraints of cassava production in the district of Glo in Benin.

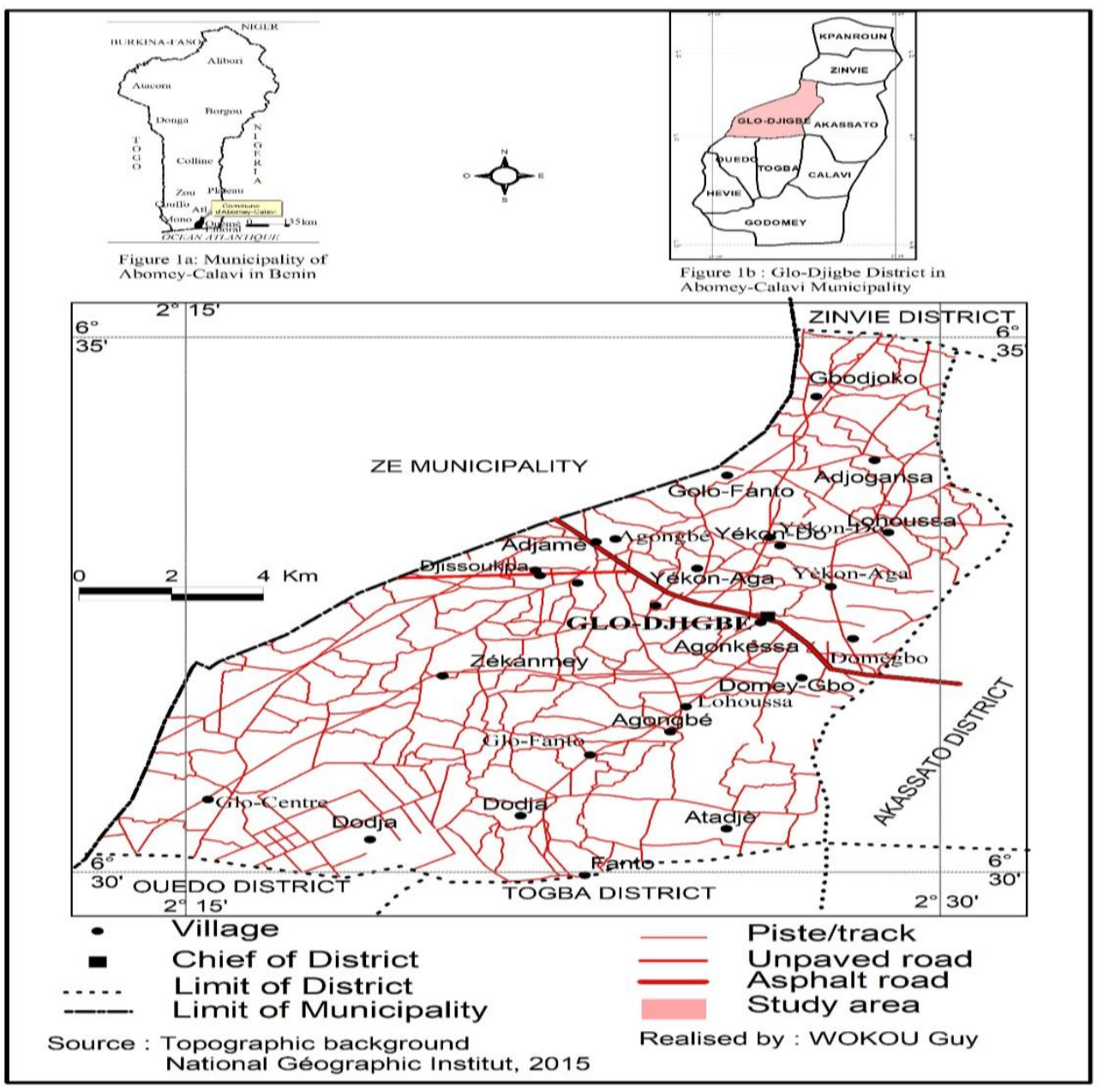


Figure 1: Geographic location of the research environment

\section{DATA AND METHODS}

The data used for this study are: data on cassava cultivation techniques. They made it possible to have a perfect knowledge of cultivation techniques; climatological data: these are the monthly and annual rainfall amounts for the municipality of Abomey-Calavi which were extracted from the database of the Agency for Air Safety and Navigation in Africa and Madagascar (ASECNA ) over the period from 1985 to 2015 . They made it possible to determine the ecological conditions of the study area; the socio-demographic data of 2002 and 2013 with an estimate in 2025 taken from the INSAE databases which made it possible to determine the sampling and socioanthropological data from field surveys.

\section{2-1 Field investigations}

The field survey was made possible by the determination of the sample.

\section{2-1-1-Determination of the sample size}

The fieldwork consisted of submitting the selected people to the questionnaires developed. These questionnaires contained questions on cultivation practices, the different cultivated varieties, production factors and profitability of their activities. The target population of this study is made up of producers and processors of cassava and its derivatives. The people interviewed were selected on the basis of information gathered from officials of the district of Golo.

Table I shows the villages of the district of Golo and the number of producers by villages selected for the field survey. Analysis of this table shows that in total, 100 producers were surveyed in this arrondissement.

Table I: Villages in the district of Golo and the number of producers surveyed by villages

\begin{tabular}{|l|c|c|c|}
\hline \multirow{2}{*}{\multicolumn{1}{|c|}{ Villages }} & \multicolumn{2}{c|}{$\begin{array}{c}\text { Nombre de personnes } \\
\text { enquêté }\end{array}$} & \multirow{2}{*}{ Total } \\
\cline { 2 - 3 } & Hommes & Femmes & \\
\hline Golocentre & 04 & 03 & 07 \\
\hline Agongbé & 02 & 03 & 05 \\
\hline Djissoukpa & 07 & 03 & 10 \\
\hline Domey-GBo & 03 & 04 & 07 \\
\hline GoloDjigbé & 08 & 04 & 12 \\
\hline GoloFanto & 03 & 09 & 12 \\
\hline Lohounssa & 03 & 07 & 10 \\
\hline Yèkon- Do & 06 & 08 & 14 \\
\hline Yèkon- Aga & 09 & 05 & 14 \\
\hline Zèkanmey & 02 & 07 & 9 \\
\hline \multicolumn{1}{|c|}{ Total } & 47 & 53 & 100 \\
\hline
\end{tabular}


Source: Determination of sample size, March 2021

A total of 100 people were surveyed as part of this research.

\section{2-1-2-Data collection technique and tools}

Several techniques are used during investigations in a real environment. The Active Participatory Research Method (MARP) is used to collect information from producers. This method made it possible to receive information from them through their knowledge and vision on cassava cultivation. Direct observation provided insight into the condition of some cassava and the course of activity in this study environment. The individual interviews allowed to know the current management mode of cassava in the environment. In addition, the data collected during the interviews made it possible to compare and supplement the information collected during the documentary research phase.

In addition, the tools were used during this field survey phase. These are: survey questionnaires sent to producers; a digital still camera used to take the illustrative photos.

\section{2-2-Processing and analysis of results}

After the fieldwork, the quantitative data was processed manually while the quantitative data was processed using Excel version 2010. The SPSS 2010 software was used for the statistical analysis of the data. All this made it possible to obtain graphs and tables. The various pieces of information were mapped in collaboration with the cartographers. The PEIR model is used for the analysis of the results obtained.

\section{2-3- Results and discussion}

\section{2-3-1-Cassava cultivation technique}

This part lists the preparation of the soil, the preparation of the cuttings, the method of preserving the stems, the cuttings, the maintenance of the plantations and the harvest.

In the district of Golo Djigbé, producers practice traditional cultivation. It is a method of cultivation that is passed on from generation to generation and includes several activities.

\section{2-3-1-1-Soil preparation}

It consists of cleaning the fields before planting new crops. This involves clearing with incineration of fallow land and weeding of stubble from previous crops.

During the high agricultural season, soil preparation begins for nearly $75 \%$ of the peasants who want to clear a fallow, then in April for the cleaning of fields cultivated the previous season and lasts until May.

During the short agricultural season, soil preparation covers the months of August September. It should be noted here that the cassava production cycle (12 months maximum) does not allow the cultivation of cassava in the first and second agricultural seasons on the same plot during the 
same agricultural season. These preparation methods vary depending on the nature of the soil, vegetation and terrain. Photo 1 shows some tools used for soil preparation.

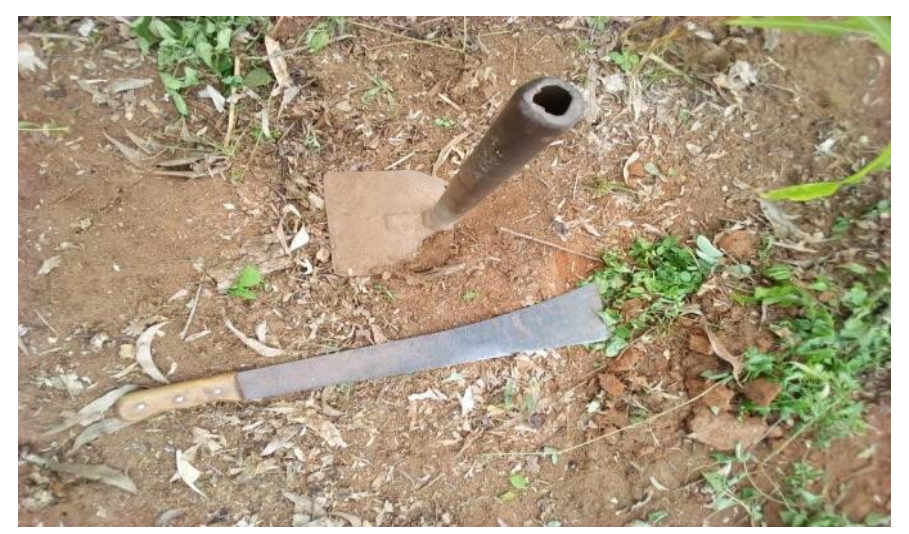

Photo 1: Tools used

Shooting: WOKOU, 2020

Photo 1 shows tools used (hoe and cutter) to clean the fields before planting new crops. This involves clearing with incineration of fallow land and weeding of stubble from previous crops.

Preparation of cuttings

It consists of planting cuttings which are portions of cassava stems cut in length from 20 to 25 $\mathrm{cm}$ and bearing an average of 4 to 6 nodes taken from healthy plants aged 8 to 18 months. It should be taken from healthy plants to avoid spreading diseases or pests that could be multiplied by cuttings. The pieces of tubers are planted at the end of the dry season which corresponds, for example for Africa in around October. Plate 1 shows the cassava cuttings.
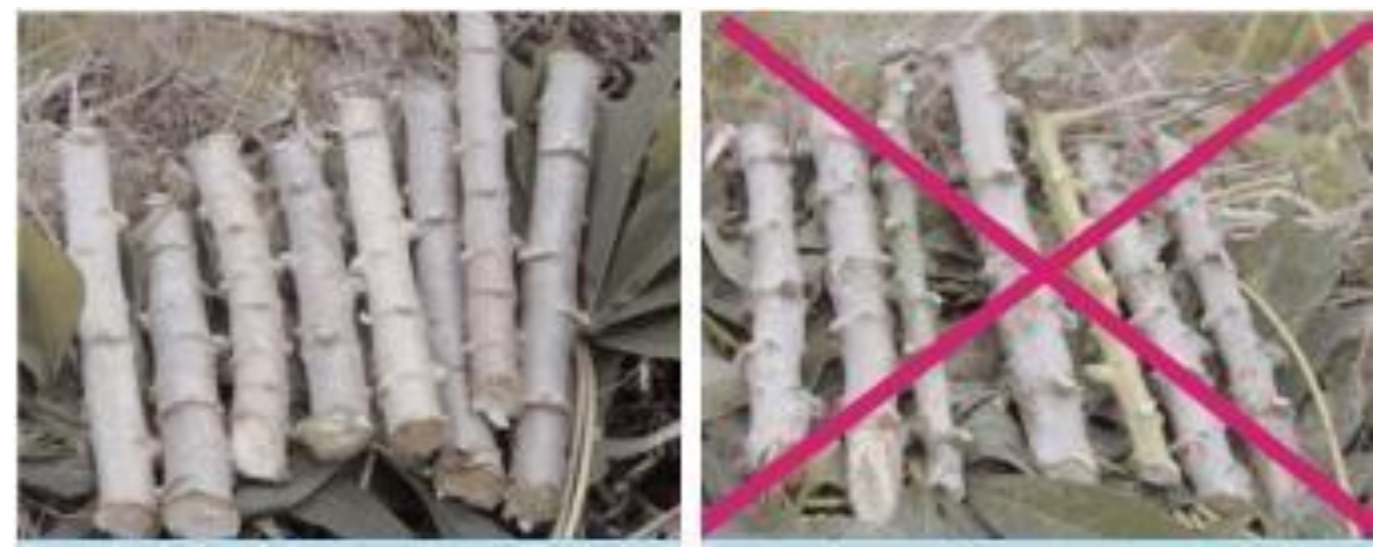

Plate 1: Cassava cuttings

Shooting: WOKOU, 2020 
Plate 1 shows the cuttings which are portions of cassava stems cut in length from 20 to $25 \mathrm{~cm}$ and bearing an average of 4 to 6 nodes taken from healthy plants aged 8 to 18 months. It should be taken from healthy plants to avoid spreading diseases or pests that could be multiplied by cuttings. The pieces of tubers are planted at the end of the dry season which corresponds, for example for Africa in around October.

\section{2-3-1-2-Stem preservation method}

Cassava growers have a method of conserving the stems, this method consists of tying the cassava stems into bundles and placing them in a vertical position under an old shelter there or in the open under the sun. Then they dig the older end of the stems into the ground and water as needed. It should be noted that these bulldozers can be kept for about a month in the ground under the sun. But this method of storing cuttings does not allow growers to recover all their cuttings in due time, as some of them dry up and rot in the hot sun. After the conservation of the stems, the producers proceed to the planting of twenty-five (25) cuttings $400 \mathrm{~m} 2$ / ha. This is why some growers like to keep their cuttings in a safe place to avoid loss.

\section{2-3-1-3-Plantation maintenance}

Cassava is easy to grow but it is necessary to work well, the soil, loosen it so that the roots develop without hindrance given the fact that it is often cultivated with other crops with a faster maturity (maize, okra, peanut). This involves weeding by removing the weeds with the hoe. This is two to three times of weeding before harvest, depending on the density of weeds. Photo 2 shows a cultivated field in Golo-Djigbé.

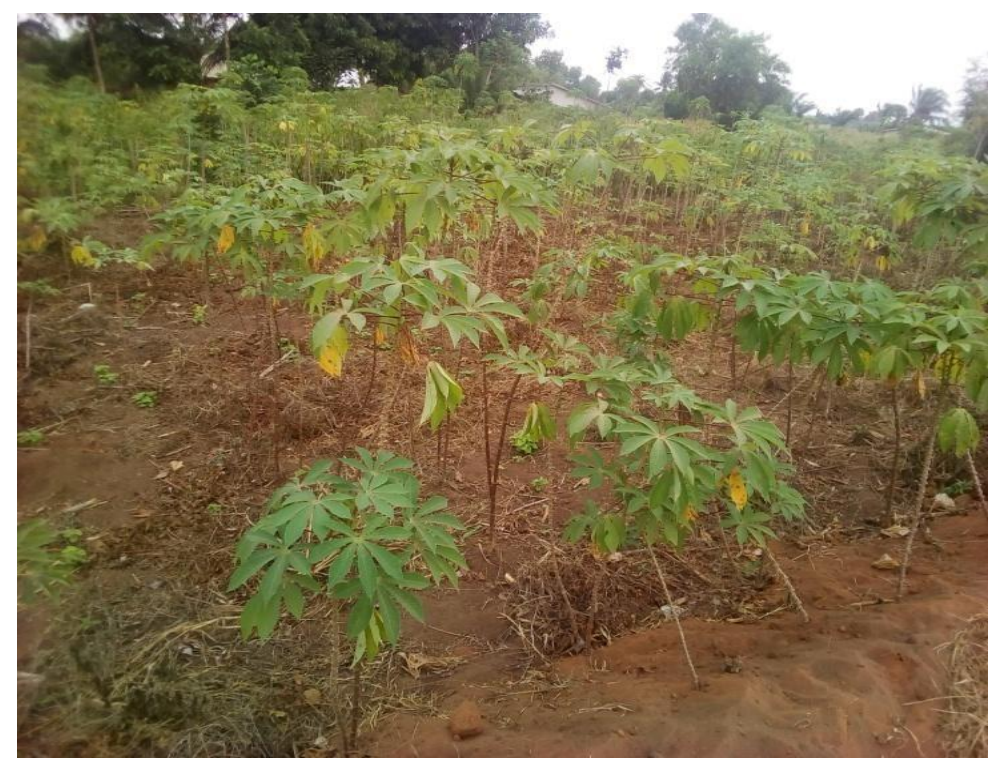

Photo 2: Field maintained in Golo-djigbé (yèkon)

Shooting: WOKOU, 2020 
Photo 2 reveals a cultivated field in Yèkon. This consists of weeding by removing the weeds using the hoe. This is two to three times of weeding before harvest, depending on the density of weeds.

\section{2-3-1-4 - Harvest}

Harvesting is done manually and starts from 7 to 8 months after planting. Harvests are made as and when needed, it is done by pulling the roots from the ground. According to some producers in the said arrondissement, the harvest can be done in the twelfth (12) months or be spread over more than sixteen (16) or even twenty-four months if it is the sweet variety. After the harvest, the tubers are sold to women processors, who will transform into derived products. A cultivated kanti is at $6000 \mathrm{f}$ or $7000 \mathrm{f}$ in the rainy season 10,000 and $15,000 \mathrm{f}$ in the dry season.

The shrub forms arborescent tufts reaching 3 or 4 meters in height, with a root system made up of creeping roots which become tuberculous which are the object of crops intended for consumption: the brown tuberculous roots with white flesh can reach $50 \mathrm{~cm}$ long and about ten centimeters in diameter. Alternate, palmate $30-40 \mathrm{~cm}$ long leaves have 5-7 lobes, and their 5$25 \mathrm{~cm}$ long petioles are dark red. Small, yellowish unisexual flowers in panicles develop with male flowers at the tips. Then fruits in capsules are formed in which the seeds are lodged. All parts of cassava produce a white latex, toxic milky juice that contains linamarin as part of the cyanogenic glycosides causing chronic to acute poisoning which can lead to death, which requires the bitter cassava to be detoxified, i.e. say grated, washed, dried and cooked before being consumed: in general, cooking is sufficient, allowing the level of linamarin to be substantially reduced. Sweet cassava contains very little of it and therefore cooks more easily. Plate 1 shows the varieties of cassava harvested.

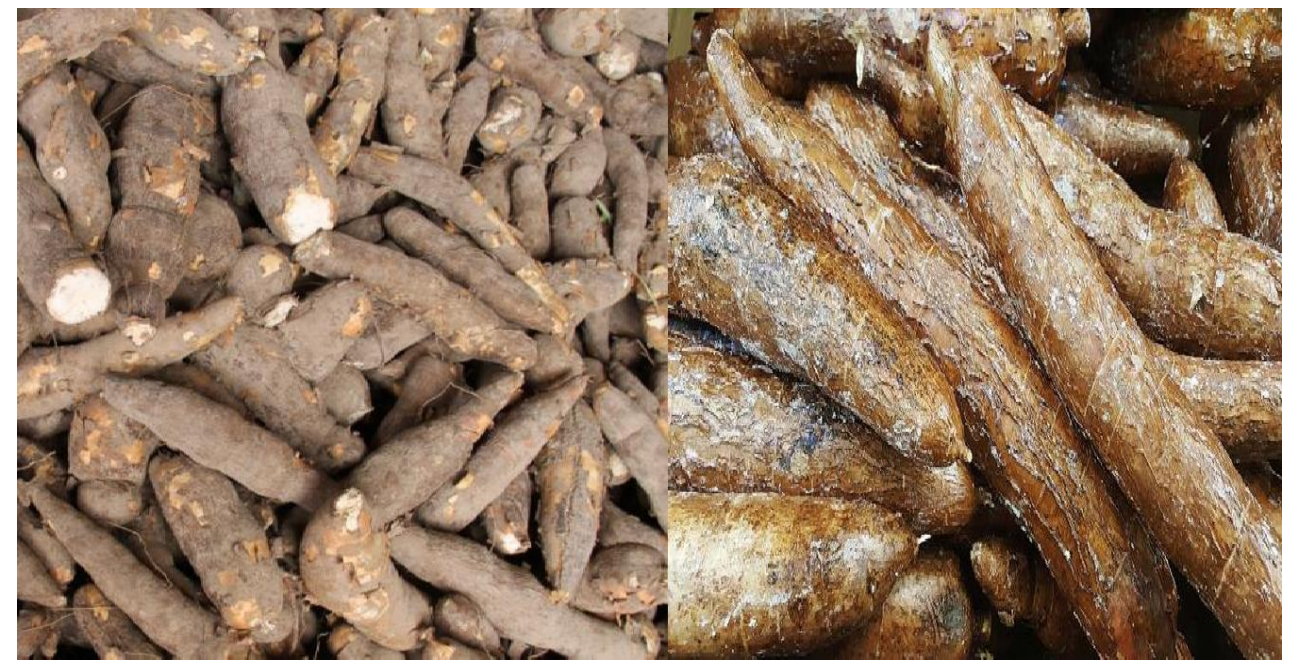

Plate 1: Cassava varieties harvested

Shooting: WOKOU, 2020 
Plate 2 shows a variety of harvested cassava. We distinguish the very toxic bitter cassava, requiring preparation to make it edible, and sweet cassava which contains almost no toxic substances. There are many cassava cultivars selected for their yield, ease of storage, resistance to disease and pests.

\section{2-3-2 - Constraints linked to cassava cultivation in the district of Golo Djigbé}

In the current state of the production system integrating cassava cultivation, several elements constitute brakes on cassava production in the study sector. In the study area and according to the results of surveys at producer level, the constraints related to cultivation are enormous.

\section{2-3-2-1- climatic and pedological constraints}

The climate handicaps constitute the natural constraints to the cultivation of cassava.

Cassava is therefore a crop very vulnerable to the water deficit of the soil during the three months following its planting. Water stress at any time during this initial period dramatically reduces root and young shoot growth compromising subsequent tuberous root development even if drought stress is subsequently remedied (FAO 2013). However, climatic hazards such as drought often lead to long drought in this study area.

This phenomenon causes the cuttings to dry out, which can no longer grow leaves or their uprooting, especially during the first two weeks of grazing.

As for the pedological requirements, we note the poverty and infertility of the soils which represent real problems facing cassava production in this locality.

Despite their efforts they still get low returns

\section{2-3-2-2- Social and economic constraints}

The insufficient abundant labor force, the lack of credits and microcredits, the lack of supervision of producers and the misuse of income represent the socio-economic factors that influence cassava production in the said arrondissement.

The reclamation of land with rudimentary techniques and the insecurity of producers on the land they exploit is a factor limiting cassava production but also the loss of land fertility.

The poor organization of the postman (land) and the insufficiency of human resources represent real socio-humanitarian constraints.

The taking of agricultural land for the benefit of the construction of the airport. Illegal occupation of the land prevents producers from expanding their fields in a context where the practice of cultivation techniques is already reducing yields. This makes access to land difficult. Added to this is the problem of lack of land which from time to time becomes thorny 


\section{2-3-2-3- Human constraints}

With regard to human constraints, it should be noted the insufficiency of human resources which translates into the glaring lack of manpower which, being insufficient, is also aging and unqualified, the insufficiency of basic management staff.

The absence of support staff at the base represents an essential obstacle to the supervision and particular monitoring of producers in this locality. This limits the emergence of the cassava industry in the said arrondissement. The lack of agricultural cash at village or even district level. Ultimately, the sharp reduction in cultivable land, the under-equipment of producers and difficult access to credit constitute the major constraints which slow down agricultural production and especially cassava in this locality.

In addition, certain diseases constitute a real obstacle to the production of cassava. These are diseases such as: cassava mosaic disease, cassava vascular bacteriosis, to which are added wild animals such as rats which dig holes and eat tubers and other pests which are insects that regularly attack stems and leaves and destroy cassava. The most well-known pests are: rats, partridges, cassava scale rabbits, cassava green mite, termites.

According to $75 \%$ of the people surveyed, they underline that certain domestic animals such as sheep, pigs, and especially the oxen of the Fulani constitute major constraints for cassava cultivation because the latter enter the fields and destroy the entire cassava field.

\section{2-3-3-Adaptation measure of farmers in the face of the constraints of cassava production in the district of Golo}

In the study area, the agricultural households surveyed do not have a perfect knowledge of the destructive cassava diseases and pest insects. So the farmers surveyed have no means to stop diseases and pests.

But according to documentary research there are several ways to fight against different diseases and insect pests. According to (FAO 2013) it is necessary:

- Plant resistant or tolerant varieties if available; in areas where the mite is endermic, treat cuttings with a locally recommended and approved insecticide;

Promote good plant establishment by planting at the start of the rainy season.

Foliar spraying of pressurized water to reduce mite populations in the case of mealybugs, you must:

Monitor cassava plantations every 2 to 4 weeks to detect focal points of infestation;

Cut and burn the infested parts of the plants; 
To fight against the wild animal pests identified in the said arrondissement, the farmers of this arrondissement use means such as:

- Traps to limit pest animals;

Hunters to kill these pest animals;

The delimitation or weeding of two (2) meters around the crop fields to escape pest animals.

Regarding pest domestic animals, the producers: Seek the help of town criers that the village chief sends to warn the breeders in order to put the animals in enclosures.

With regard to the oxen, the peasants convene these herders in order to take effective measures to reduce the damage of the latter on the cassava crop. To solve the problems of infertility and soil poverty of the peasants surveyed $4 \%$ leave the land fallow for 2 to 3 years and others resort to the use of chemical fertilizers $15 \%, 25 \%$ change the crop altogether cassava in groundnut or bean crops for 1 to 2 years and 56\% adopt plowing. Figure 2 illustrates the proposal of the different means to solve infertility problems

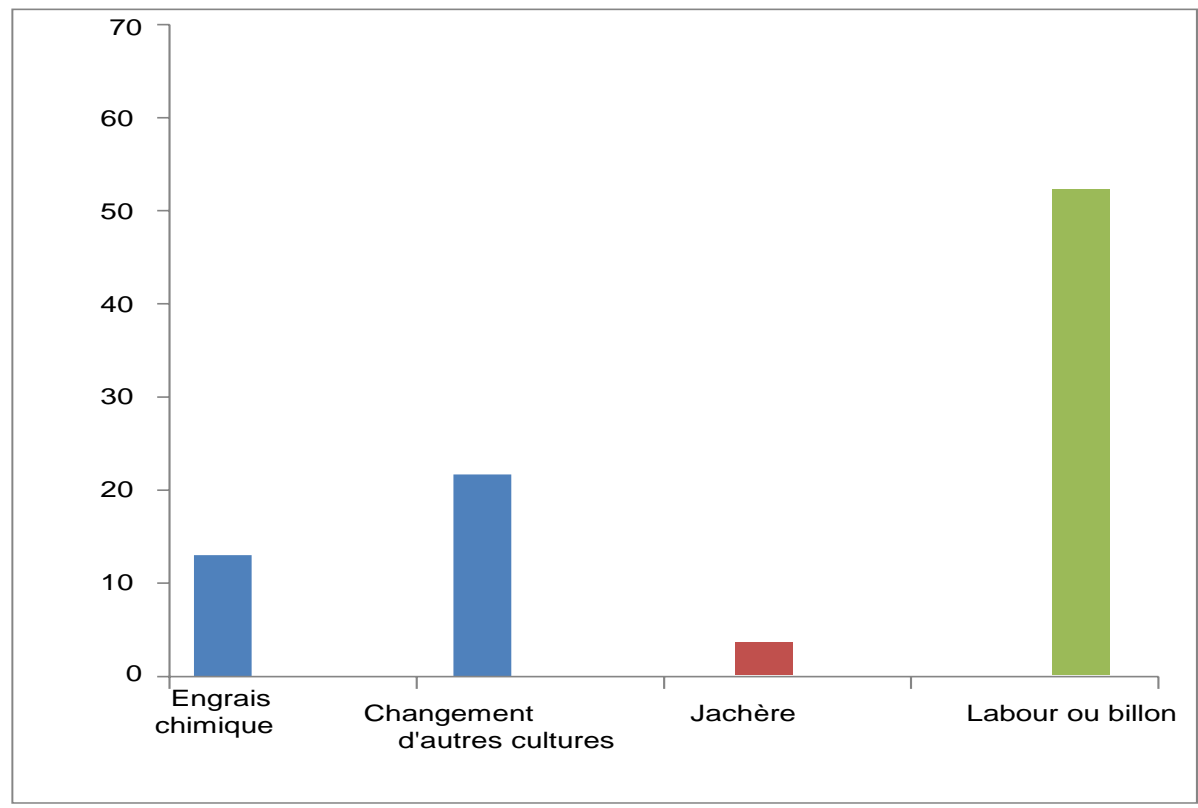

Figure 2: Proportions of the different methods to regulate soil infertility

Data source: Field survey 2020

The analysis in Figure 2 shows the proportion of different methods farmers use to solve soil infertility problems. It emerges from the analysis of Figure 6 that $4 \%$ leave their soil fallow, $15 \%$ use chemical fertilizer to make their soil fertile, $25 \%$ change their soil to another crop and finally $56 \%$ do the plowing or billon to settle the infertility of their land. It emerges that the populations of the said arrondissement more adopt plowing or ridging to resolve soil infertility problems. Figure 2 illustrates the methods of acquiring cultivable land in the research environment. 


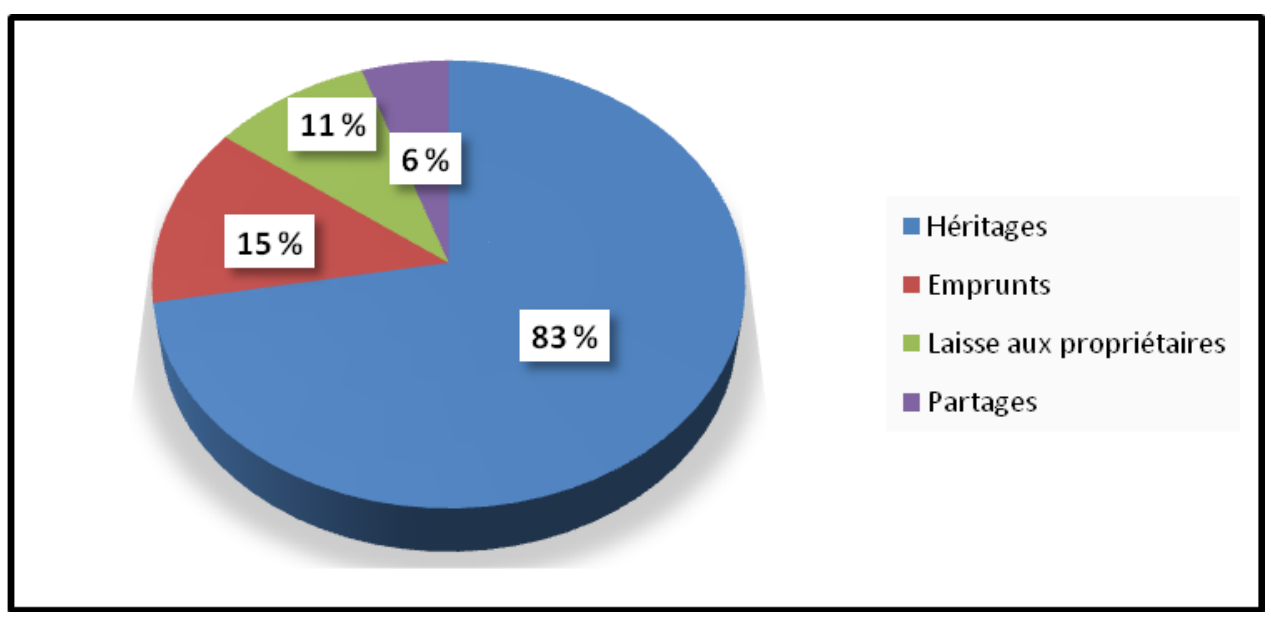

Figure 2: Means of acquiring cultivable land

Data source: Field survey, July 2019

From the observation of figure 2, it emerges that $83 \%$ of the peasants questioned are landowners who inherit land and 15\% rent the land from landowners and pay 50,000f per hectare (loans) for a year $11 \%$ leave the land to the owners in the event of a claim and $6 \%$ divide the agricultural products into two parts, of which $1 / 3$ of these products go to the landowner and $2 / 3$ to the producers. All these means of acquiring cultivable land make it possible to deal with land problems in the research environment.

\section{CONCLUSION}

This research is a contribution to a better understanding of the constraints linked to cassava production in the Arrondissement of Golo-Djigbé (municipality of Abomey Calavi). It should be remembered that the cultivation of cassava requires the respect of certain conditions which are: the preparation of the ground, the planting material, the planting period, the rotation of the crop, the association-rotation, the association and the rotations are carried out in the locality. These various modes of use of space determine the nature of the crops according to whether they are abundant or weak. Cassava varieties can be classified into two categories: the sweet variety, and the bitter varieties. Also the profitability of cassava production and derivatives contributes to improving the living conditions of producers. They also process cassava derivatives such as gari which is heavily consumed in Benin, tapioca, fufu and bread, a source of wealth for these producers. In addition, some constraints, in particular the unavailability of cultivable land, the lack of financing, poor organization of producers, the aging of the workforce, the lack of mastery of modern production techniques, the lack of agricultural training, soil poverty and climatic constraints are all elements which constitute a handicap for the promotion of the sector which is the main lever of development in the district. The strategies proposed both in terms of production 
Vol. 06, No. 03; 2021

ISSN: $2456-8643$

constitute palliatives that can make cassava production activities a source of improving the living conditions of the populations in the said arrondissement.

\section{REFERENCES}

Agbandjï C.T. (2015): Production and marketing of cassava in the municipality of Abomey master's thesis in geography, DGAT / FLASH / UAC, 67p.

Ahossi R. (2008): Cassava cultivation and its socioeconomic effects in the commune of kétou. Master's thesis in geography, DGAT / FLASH / UAC, 99p.

Fadeyi (2012): Cassava production and processing in the commune of kétou: Strengths and perspectives. Master's thesis in geography, DGAT / FLASH / UAC, 91p

FAO (2013): producing more with less cassava, 128p.

LARES-Bénin (2013): cassava value chain in Benin, 70p 